\title{
Synthesis and Characterization of Silicone epoxy resin /poly (methyl methacrylate) Interpenetrating Polymer Networks
}

\author{
D.Hussinaiah ${ }^{1}$, M.Prasad ${ }^{2}$, K.Mohanaraju ${ }^{2}$, and A.B. Samui ${ }^{3}$ \\ 1.Axalta Coating Systems India Pvt.Ltd., Plot No.KV-1/2, Savli GIDC, Vadodara-391775 India. \\ 2. Dept of Polymer Science, S.K.University, S.V.puram post, Anatapur-515003 India. \\ 3. Naval Materials Research Laboratory, Anand nagar post, Shil-badlapur road, Ambermath-421 506. Thane \\ dist. India ${ }^{2}$.
}

\begin{abstract}
Semi interpenetrating networks (IPNs) of the Silicone epoxy resin and poly (methyl methacrylate) (PMMA) were prepared by the sequential mode of synthesis. These were characterized with respect to their mechanical properties, namely, tensile strength, elongation at break. Thermal properties were studied by differential scanning calorimetry, thermogravimetry and dynamic mechanical thermal analysis. The morphological features were studied through scanning electron microscopy(SEM). The effects of variation of the blend ratios between silicone epoxy and poly(methyl methacrylate) on the above-mentioned properties were examined. There was a gradual increase of tensile strength with consequent increases in elongation at break for both types of IPNs with increases in PMMA content up to $30 \%$ and further the above properties were decreased with increasing PMMA. The weight retentions in the thermal decomposition of both the semi-IPNs and full IPNs were higher than the silicone epoxy system. This enhancement was would be related to the presence of the unzipped methyl methacrylate monomer, which acted as radical scavengers in the silicone epoxy degradation. An inward shift and lowering (with respect to pure epoxy) of the Tg of the IPNs was observed. The fractography as studied by SEM shows change in fracture mechanics from shear yielding to crazing with increasing PMMA content.
\end{abstract}

Key Words: - Epoxy Resins, Silicone Epoxy Resin, Interpenetrating networks, Acrylates

\section{INTRODUCTION}

Interpenetrated polymer networks (IPNs) are the special class of blends, in which at least one polymer is synthesized and/or crosslinked in the immediate presence of the other ${ }^{1-4}$. IPNs can be produced with a broad range of properties from toughened elastomers to high impact polymers. Then IPNs are highly promising materials for marine applications as protective coating binders to have both corrosion resistance and weathering performance ${ }^{5}$. Epoxy resins are widely used in marine applications as coatings, adhesives and composites etc. However, epoxy resins on crosslinking with amine hardeners; it exhibits brittle and it leads to poor performance. Several approaches were made to improve the toughness and performance as coatings binder, emphasis was placed on synthesis of silicone epoxy resin and its IPNs to improve their toughness and binder performance ${ }^{6-10}$. Through silicone modification, silicone epoxy resins are proved for its thermal, mechanical and surface properties. Thermoplastic resins such as PMMA are tougher materials and having excellent weathering properties as compared to epoxy resins. The high fracture toughness of PMMA is not unexpected, because the large free volume available in these amorphous materials allows them to absorb the energies associated with crack growth and propagation ${ }^{11}$.

The present study is an attempt was made to synthesize and characterization of silicone epoxy/poly(methyl methacrylate) semi IPNs. The incorporation of poly(methyl methacrylate) dispersion into silicone epoxy network system was made by sequential IPN synthesis method ${ }^{12-15}$. These synthesized IPNs were characterized for changes in its structure by FTIR spectro photometer. Their mechanical, thermal and morphological characteristics discussed. Also, discussion made on its corrosion resistance behavior for few binders, which are optimized at their good mechanical and thermal properties.

\section{EXPERIMENTAL}

\subsection{Materials}

Diglycidyl ether of biphenyl -A (Epoxy resin, GY-250, epoxide equivalent weight $190-200$; M/s.Hindustan Ciba Geigy, India), Silicone resin (poly methyl phenyl siloxane, DC-840, Dow Corning, India), Modified cycloaliphatic amine (Ancamine -2280, Amine equivalent weight 110, Air Products \& Chemicals Inc., USA), $\gamma$-Amino propyl triethoxy siloxane ( $\gamma$ - APS, Aldrich chemicals, USA), Dibutyl tin dilaurate (Aldrich), Ethylene glycol dimethacrylate (Aldrich), AIBN (BDH, India) were used as received. All the chemical were used as received. Solvents, chlorobenzene, chloroform, acetic acid are procured from Ranboxy Chemicals India. 
The solvents were also used as received. Monomers methyl methacrylate procured from Fluka, India. Monomer was purified on before its use.

\subsection{Synthesis of Silicone epoxy resin}

Synthesis of silicone epoxy resin by using diglycidyl ether of Bisphenol-A epoxy resin with hydroxylated silicone was discussed by Anandkumar ${ }^{6}$ in his studies for anti-corrosive applications. The same procedure was adopted to made silicone epoxy resin. In a $250 \mathrm{ml}$ three necked round bottom flask, $100 \mathrm{gm}$ of epoxy resin (GY 250), $10 \mathrm{gm}$ of silicone resin (DC 840) was added under agitation. To this $0.1 \mathrm{gm}$ of $\gamma$-APS and catalyst, $0.01 \mathrm{gm}$ of dibutyl tin dilaurate was added. Then the reaction mixture was heated up to $90^{\circ} \mathrm{C}$ and it was maintained for $1 \mathrm{hr}$. The resulted pre-polymer mixture was subjected to vacuum to remove entrapped air and accelerate the condensation reaction between $\gamma$ - APS and hydroxyl terminated poly (methyl phenyl siloxane). Then the resultant silicone epoxy resin was degassed for removal of ethanol formed during the condensation process. The scheme of silicone epoxy resin synthesis setup is shown in Fig.1

\subsection{Synthesis of Silicone epoxy / poly(methyl methacrylate) semi IPNs}

Semi IPNs of silicone epoxy / poly(methyl methacrylate)s made by using sequential mode of synthesis $^{14}$. A $250 \mathrm{ml}$ four necked round bottomed flask was equipped with thermometer, mechanical stirrer, condenser and nitrogen purging. 130 gm of silicone epoxy resin (100/30 of epoxy / silicone) was added into the round bottom flask under stirring. To this $0.1 \mathrm{gm}$ of AIBN and10 gm of methyl methacrylate monomer mixture was added under stirring, ensured that, the initiator was dissolved completely in the monomer, before adding this mixture into the flask. Then the temperature of the kettle was heated up to $80^{\circ} \mathrm{C}$ under nitrogen purging and it was maintained for $1 \mathrm{hr}$. The resulted reaction mixture was allowed to cool down to room temperature. The stoichiometric amount of amine curing agent for silicone epoxy resin was added to the reaction mixture and thoroughly mixed. The resultant was poured in Teflon mold and degassed for $15 \mathrm{~min}$. to remove entrapped air during the mixing process. The semi IPNs were cured at room temperature for seven days and further post cured at $80^{\circ} \mathrm{C}$ for 6 hours. Various semi IPNs were prepared by increasing the concentration of methyl methacrylate monomer and the results were tabulated in table 1. The schematic representation of silicone epoxy /poly (methyl methacrylate) of different semi IPNs is presented in Fig.2.

\subsection{Preparation of Silicone epoxy/poly(methyl methacrylate) semi IPNs free films and coating system}

Siloxane epoxy/ poly(methyl methacrylate) semi IPN free films and coating system were prepared by using silicone epoxy resin and the hardener modified cyclo aliphatic amine respectively. Based on stoichiometric equivalent (Table 1), calculated amount of curatives was sequentially added to the silicone epoxy / poly(methyl methacrylate) blend. The resulting product was directly poured in Teflon mould to get semi IPN free film and also coated over mild steel specimens at $30{ }^{\circ} \mathrm{C}$. The semi IPNs free films and coated specimens were cured at room temperature for seven days and further post cured at $80^{\circ} \mathrm{C}$ for 6 hours. Various semi IPNs free films and coated specimens were prepared by increasing the concentration of methyl methacrylate monomer and the results were tabulated in table 1.

\section{METHODS}

Infrared spectra were recorded on a Perkin-Elmer model 1600 spectro photometer, by smearing of liquid samples on $\mathrm{KBr}$ pellet. Cured films of semi and full IPNs with 5 to 6 mils of thickness were directly used for FT-IR spectroscopy.

Tensile properties of silicone epoxy / poly (methyl methacrylate) semi IPNs were measured by using Universal testing machine (Hounsfield, model $50 \mathrm{KS}$ ). Specimens, in the form of stripes of $15 \mathrm{~mm}$ width, were cut from cured film. A gauge length of $25 \mathrm{~mm}$ was maintained between grips and film specimens were strained at a rate of $10 \mathrm{~mm} / \mathrm{min}$. Before performing the test, specimens were conditioned for $40 \mathrm{~h}$, at $50 \%$ relative humidity. For each composition, ten specimens were examined and results of five highest readings of peak load were used for calculation of tensile strength.

Thermal degradation of silicone epoxy / poly (methyl methacrylate) semi IPNs were estimated by using Thermogravimetric analyzer (TA instruments, Hi 2950). The samples ranging from $8-12 \mathrm{mg}$ in weight were heated at the rate of $20^{\circ} \mathrm{C} / \mathrm{min}$ in nitrogen atmosphere. The temperature maintained from $30^{\circ} \mathrm{C}$ to $800^{\circ} \mathrm{C}$ for all IPNs Glass transition temperature of silicone epoxy / poly (methyl methacrylate) semi IPNs were measured by using Differntial scanning calorimetry (TA instruments, Q -100). The samples ranging from $12-16 \mathrm{mg}$ were weighed in hermetic aluminum pans, sealed in each measurement. The dynamic scans were performed from $20^{\circ} \mathrm{C}$ to $180^{\circ} \mathrm{C}$ with ramp of $10^{\circ} \mathrm{C} / \mathrm{min}$ in nitrogen atmosphere.

The dynamic mechanical properties of silicone epoxy / poly (methyl methacrylate) semi IPNs were evaluated by using dynamic mechanical analyzer (Rheometric Scientific, model 3E) at a heating rate of 
$10^{\circ} \mathrm{C} / \mathrm{min}$ in the temperature range of $-100^{\circ} \mathrm{C}$ to $250^{\circ} \mathrm{C}$. Frequency of $1 \mathrm{~Hz}$ was used during measurement under tensile mode.

Scanning electron microscopy (SEM) was performed in a JEOL JSM-L5300 microscope (Tokyo, Japan), using an accelerator power of $10 \mathrm{kV}$. The samples were fractured and the surface was treated with tetrahydrofuran (THF) for around $15 \mathrm{~h}$ at room temperature to extract the PMMA phase. Then, the dried surface was coated with a thin layer of gold and analyzed with the help of a secondary electron detector.

The impedance measurements for silicone epoxy / poly (methyl methacrylate) semi IPNs were carried out using Gamry CMS 300 electrochemical impedance system. In this study, $3.5 \% \mathrm{NaCl}$ solution was used as electrolyte and the exposed sample area was $21.5 \mathrm{~cm}^{2}$. Three electrodes system having saturated calomel electrode (SCE) as reference electrode, sample as working electrode and platinum as counter electrode was employed. A sine wave of $10 \mathrm{mV}$ (r.m.s) was applied across the cell. The measurements were made in the frequency range of $50 \mathrm{kHz}$ to $0.02 \mathrm{~Hz}$. EIS study was carried out on samples after various exposure intervals.

\subsection{FTIR Spectroscopy of Silicone epoxy/PMMA semi IPNs}

Structural elucidation of silicone epoxy / Poly (methyl methacrylate) semi IPNs were made for different IPNs with 10, 30 and 50\% ratio of PMMA in silicone epoxy networks. The IR spectrums for epoxy, silicone epoxy and semi IPNs were shown in Fig.3. As per the figures the characteristic peaks of different groups presented in Table-2. The presence of $\mathrm{OH}$ peak in the epoxy resin and absence of $\mathrm{NH}_{2}$ peak of $\gamma$-APS after crosslinking indicates the incorporation of both the above resins in the semi IPNs. Further the reduction in the intensity of the epoxy group around $830 \mathrm{~cm}^{-1}$ in the silicone epoxy resin indicates the crosslinking of the epoxy group in the final semi IPNs with modified cycloaliphatic amine crosslinker.

\subsection{Tensile \& Elongation properties of Silicone epoxy/PMMA semi IPNs:}

For semi silicone epoxy/ poly (methyl methacrylate) tensile and elongation properties have been studied as a function of blend ratios of silicone epoxy and PMMA. The tensile strength and elongation of semi IPNs has been represented in Figs. 4 and 5 taking into consideration by influences of crosslinking and with increasing the content of dispersed PMMA. The tensile and elongation properties of semi IPNs have been tabulated in Table 3. The tensile properties of semi IPNs, were observed under the influence of dispersed poly (methyl methacrylate) where only silicone epoxy is crosslinked. In a semi IPNs the tensile strength increases with increasing poly (methyl methacrylate), this can be seen that in Fig.4. The increased tensile properties of semi IPNs were explained due to the formation of increased degree of IPN between the molecular threads of silicone epoxy and poly (methyl methacrylate). \%Elongation for semi IPNs increases uniform by with increased content of dispersed PMMA as shown in Fig.5. This was due to the dispersed PMMA content is there by plasticity is increases in Semi IPN system. Authors Mahesh ${ }^{16}$ and $\mathrm{Hsieh}^{17}$ et al were observed similar behavior of the increasing tendency in tensile strength with the incorporation of bismaleimide into epoxy system as well as incorporation of polyurethane into epoxy system.

\subsection{Thermo Gravimetric Analysis of Silicone Epoxy/PMMA semi IPNs:}

The thermo gravimetric curves for silicone epoxy resin, semi IPNs were presented and compared as shown in Fig.6. In semi silicone epoxy / poly(methyl methacrylate) IPNs an enhancement of weight retention observed as compared to that of silicone epoxy resin. The degradation temperatures and weight retention of both semi and full IPNs of silicone epoxy / poly(methyl methacrylate) are tabulated in table 4. The weight retention $(\approx 98 \%)$ at the first stage of degradation for both semi and full IPNs are needed high temperature as compared to silicone epoxy.

Thus, it may be presumed that the present IPN systems may have little influence on the degradation mechanism. It may also be assumed that the effect of interpenetration almost negligible on the course of thermal degradation. However, the composition of an IPN plays dominant role in determining the course of degradation and $\%$ weight loss. Particularly, in the degradation process the products of one polymer have the possibility of interaction with that of the second polymer, thus blocking of the polymerization of the second polymer. In fact, the silicone epoxy / poly(methyl methacrylate) exhibit the enhancement of the weight retention compared to that of pure silicone epoxy resin. The thermal degradation behavior of silicone epoxy resin can be explained by non radical process of $-\mathrm{C}-\mathrm{C}$ - bond scission. In the system PMMA enhanced thermal stability of the semi IPNs may be due to the lebaration possibility of acrylate monomer unit such as MMA that may be scavenging the macro radicals or pyrolytic products of epoxy.

\subsection{Differential Scanning Calorimetry of Silicone Epoxy/PMMA semi IPNs:}

Differential scanning calorimetry (DSC) results of unmodified epoxy resin and silicone epoxy IPN systems are presented in Table 5. Silicone epoxy system exhibited single gloss transition temperature. The 
variation of $T_{g}$ value of silicone epoxy resin is insignificant, since siloxane incorporation in epoxy resin does not alter the $T_{g}$ values due to chain entanglement and its ablative character. However a slight decreasing trend is observed when siloxane is incorporated in epoxy coating systems. The DSC curves of both semi IPNs of silicone epoxy / poly(methyl methacrylate) are shown in Fig.7. Semi IPNs observed the more glass transition temperature than unmodified cured epoxy and of silicone epoxy. This is attributed to more threading or interpenetration in semi IPNs. The glass transition temperature values have increased first with excess amount of poly (methyl methacrylate) and then decreased with further increases in PMMA amount into silicone epoxy resin matrix. This may be attributed due to highly dispersed poly (methyl methacrylate) phase acting as a plasticizer and it is reducing the stiffness in IPNs. The extent of higher Tg values irrespective of both semi and full IPNs appears to be much higher than that of calculated from Fox equation or by weight average formula ${ }^{14}$.

$$
\mathrm{T}_{\mathrm{g}}=\mathrm{w}_{1} \mathrm{Tg}_{1}+\mathrm{w}_{2} \mathrm{Tg}_{2} \text { or } 1 / \mathrm{T}_{\mathrm{g}}=\mathrm{w}_{1} / \mathrm{Tg}_{1}+\mathrm{w}_{2} / \mathrm{Tg}_{2}
$$

where $\mathrm{Tg}_{1}, \mathrm{Tg}_{2}$ are the glass transition temperatures of component 1 and component 2 and $\mathrm{w}_{1}, \mathrm{w}_{2}$ are weight fraction of component 1 and component 2 respectively.

\subsection{Dynamic Mechanical properties of Silicone Epoxy/PMMA semi IPNs}

The dynamic mechanical properties of the unmodified epoxy, silicone epoxy and semi IPNs of silicone epoxy / poly (methyl methacrylate) are shown in Fig. 8 and 9. The figures shows that broader glass transition peaks as shown by the Tan $\delta$ versus temperature and the linear loss modulus, E" curves. Fay ${ }^{18}$ etal and Chang ${ }^{19}$ etal suggested that the integral value of the loss modulus versus temperature curve and wshich was called loss area is displays the properties of materials which are related to its structure. The main chain and pendent chain linked directly with the main chain make chief contributions to the damping property in the glass transition temperature region. For obtaining a broad glass transition range, it is required that the compositions are nearly miscible and that domains of these phases exhibit one broad peak. Composition with immiscible exhibit two glass transitions and two tan $\delta$ temperature peaks with relatively little damping in the area between them. Table 6, represents the integral area of loss Tan $\delta$ to temperature been shown to be related to the activation energy of backbone motion in the magnitude ${ }^{20}$. The Tan $\delta$ curve of silicone epoxy / poly(methyl methacrylate) exhibit narrow and broader peaks for semi IPNs respectively. This may be attributed that more threading or interpenetration in semi IPNs with increasing PMMA into silicone epoxy network system. A single glass transition temperature (Tan $\delta$ peak) yielded in almost all semi IPNs, it is good evidence for the molecular mixing of two net work systems. Introduction of methyl methacrylates segments through IPN formation can result high modulus material.

\subsection{Scanning Electron Microscope of Silicone Epoxy/PMMA semi IPNs}

Scanning Electron Microscope images of silicone epoxy /poly(methyl methacrylate) is shown in Fig.10-13 Poly(methyl methacrylate) concentration at 10, 30 and 50\% in silicone epoxy observed for phase separation evaluation. The surface morphology of silicone epoxy showed homogeneous micro structure, where as the fracture surface of semi IPNs of silicone epoxy / poly (methyl methacrylate) exhibited a heterogeneous morphology. These results showed that there are no phase separated domains in the silicone epoxy system and confirmed the formation of homogeneous inter crosslinked network structure. On fracture the bimodal phase separation observed in semi IPNs of silicone epoxy / poly (methyl methacrylate). In these micrographs, circular dark phases are dispersed poly (methyl methacrylate) and the lighter phase represents the glass phase of silicone epoxy resin. Essentially almost spherical poly(methyl methacrylate) domains are dispersed in silicone epoxy matrix and the sizes of these spherical domains gradually increased with increasing the amount of poly(methyl methacrylate) content in semi IPNs. The dispersed poly(methyl methacrylate) particles in silicone epoxy provides the stress concentration zones for matrix yielding and poly (alkyl methacrylate) cavitation. The cavitation around each of the particles supports earlier proposed mechanisms for enhanced toughness observed in elastomer modified thermosets ${ }^{21}$. Thus, the SEM provides physical evidence of improved energy absorption during the fracture process.

\subsection{Electrochemical Impedance Spectroscopy of Silicone Epoxy/PMMA semi IPNs}

The EIS curves of semi IPN of silicone epoxy /poly(methyl methacrylate) for un-pigmented composition (30\% Silicone epoxy /poly(methyl methacrylate) are presented in Fig.14. The polarization resistance (Impedance) readings were taken after 7,14, 21 and 28 days of exposure. Silicone epoxy/poly(methyl methacrylate) semi IPN system shown very high Impedance at 7 days $4.0 \times 10^{9}$ at this stage IPNs have excellent corrosion protection property. Later on the coatings resistace was gradually decreased to $1.4 \times 10^{5}$ after 28 days. This should be due to the water uptake of silicone epoxy/polya(methyl methacrylate) semi IPNs. 


\section{REFERENCES}

[1] L.H.Sperling, Interpenetrating Polymer Networks and related Materials, Plenum, New York 1981.

[2] D.Klempner, L.H.Sperling and L.A. Utracki, eds, Interpenetrating Polymer Networks, Adv.Chem.Ser.No.239, ACS Books, Washington, DC 1994.

[3] L.H.Sperling and V.Mishra, Polymers for Advanced Technologies, 7 (1996) 197

[4] V. Mishra and L.H.Sperling, The Polymeric Materials Encyclopedia:Synthesis, Properties and Applications, CRC Press, Boca Raton 1996

[5] S M Krishnan, Prog.Org.Coat 57 (2006) 383.

[6] S Ananda Kumar, T S N Sankara Narayanan, Prog.Org,Coat., 45 (2002) 323.

[7] P.H.Sung, C.Y.Lin., Eur.Polym.J 33 (1997) 1997.

[8] S.Bhuniya, B.Adhikari, J.Appl.Poly.Sci., 90 (2003) 1497.

[9] T.V.T Velan, I Mohammad Bilal., Bull.Mat.Sci., 23 (2000) 425

[10] Prashant Gupta, Madhu Bajpai., Adv.Chem.Eng.Sci., 1 (2011) 133.

[11] Y Robert, Ting., Epoxy resin Chemistry \& Technology., $2^{\text {nd }}$ Ed. Clayton A. May., Marcel Dekker Inc., New Yark., 1988, p552

[12] D.Chakraborthy, B.Das., J.Appl.Polym.Sci.,60 (1996) 2125

[13] B.Das, D.Chakraborthy, A.K.Hajra, S.Sinha., J.Appl.Polym.Sci., 53(1994) 1491.

[14] [D.Chakraborthy, B.Das, S.Roy., J.Appl.Polym.Sci., 67 (1998) 1051.

[15] B.Das, D.Chakraborthy., Polym. Gels \& Networks 3 (1994) 197

[16] K P O Mahesh, M Alager and S Anand Kumar, Polym.Adv.Tech,14 (2003) 137.

[17] H L Hsieh and J L Han, Polym.Sci., Poly.Phy, 28 (1990) 623.

[18] J.J.Fay, D.A Thomas and L.H. Sperling, J.Appl.Polym.Sci.,43(1991) 1617

[19] M C O Chang, D A Thomas and L H Sperling, Polym.Sci.Polym.Phys., 26 (1988) 1627

[20] B Hartman, Polym.Mat.Sci.Eng., 60 (1989) 477

[21] Y Huang, D L Hunston, A J Kinloch and C K Riew, Toughned pliastics I, CK Riew, Kinloch A J Eds: American Chemical Society, Washington, DC (1993).

Table -1: Synthesis of Silicone epoxy / poly (methyl methacrylate) semi IPNs:

\begin{tabular}{|c|c|c|c|c|c|}
\hline $\begin{array}{c}\text { Expt. } \\
\text { No. }\end{array}$ & $\begin{array}{c}\text { Epoxy/Silicone } \\
\text { resin, gm Total }\end{array}$ & $\begin{array}{c}\text { MMA, } \\
\text { gm }\end{array}$ & $\begin{array}{c}\text { AIBN } \\
(1 \% \text { of monomer })\end{array}$ & $\begin{array}{c}\text { Cyclo aliphatic } \\
\text { amine, gm }\end{array}$ & Semi IPN \\
\hline 1 & $100+30=130$ & 10 & 0.1 & 73.5 & PMMA-10\% \\
2 & $100+30=130$ & 20 & 0.2 &, & PMMA-20\% \\
3 & $100+30=130$ & 30 & 0.3 &, & PMMA-30\% \\
4 & $100+30=130$ & 40 & 0.4 & PMMA-40\% \\
5 & $100+30=130$ & 50 & 0.5 & PMMA-50\% \\
\end{tabular}

Table -2: IR spectra characteristic peaks of Silicone epoxy/PMMA semi IPNs

\begin{tabular}{|l|c|}
\hline Peak / molecular vibrations & Semi IPN, $\mathrm{cm}^{-1}$ \\
\hline $\mathrm{Si}-\mathrm{C}-$ & 739 \\
\hline Epoxy resin ring, C-O vibrations & 829 \\
\hline Epoxy resin, C-O-C ether \& ${\mathrm{C}-\mathrm{CH}_{2} \text { vibrations }}^{-}$ & 1243 \\
\hline $\mathrm{C}=\mathrm{O}$, ester carbonyl group of PEMA & 1719 \\
\hline Assymetric vibrations of -O-CH & 2885 \\
\hline OH group for epoxy resin in $\mathrm{IPN}$ system & 3425 \\
\hline Indicates the absense of $\mathrm{OH}$ group from for silicone resin & 3500 \\
\hline Indicates the absense of $\mathrm{N}-\mathrm{H}$ stretching from G-APS $\mathrm{NH}_{2}$ groups & 3300 \\
\hline
\end{tabular}


Synthesis and Characterization of Silicone epoxy resin/poly (methyl methacrylate)

Table -3: Mechanical Properties of Silicone epoxy / PMMA semi IPNs

\begin{tabular}{|c|c|c|}
\hline SEMI IPNs: & TENSILE STRENGTH & \% ELONGATION \\
\hline PMA $-10 \%$ & 42.6 & 7.6 \\
\hline PMA $-30 \%$ & 43.7 & 7.2 \\
\hline PMA $-50 \%$ & 46.2 & 7.6 \\
\hline
\end{tabular}

Table 4: Degradation temp. and \% Yield values of Silicone epoxy / PMMA semi IPNs:

\begin{tabular}{|c|c|c|c|c|c|c|}
\hline Sample & $\begin{array}{c}\text { Peak 1 } \\
\mathrm{T},{ }^{\circ} \mathrm{C}\end{array}$ & Yield\% & $\begin{array}{c}\text { Peak 2 } \\
\mathrm{T},{ }^{\circ} \mathrm{C}\end{array}$ & Yield \% & $\begin{array}{c}\text { Peak 3 } \\
\mathrm{T},{ }^{\circ} \mathrm{C} \\
/ \mathrm{Char}\end{array}$ & $\%$ Yield \\
\hline Semi IPNs & 139 & 98.2 & 318 & 85.3 & 759 & 16.4 \\
\hline Silicone epoxy / PMMA -10\% & 139 & 98.2 & 318 & 88.9 & 759 & 11.9 \\
\hline Silicone epoxy / PMMA -30\% & 139 & 98.2 & 318 & 87.1 & 759 & 11.4 \\
\hline Silicone epoxy / PMMA -50\% &
\end{tabular}

Table 5: Tg values of Silicone epoxy / PMMA semi IPNs:

\begin{tabular}{|c|c|}
\hline \multicolumn{1}{|c|}{ Sample } & Glass Transition Temp. ${ }^{\circ} \mathrm{C}$ \\
\hline Silicone epoxy resin & 76.2 \\
\hline Semi IPNs & 100.3 \\
\hline Silicone epoxy / PMMA -10\% & 113.1 \\
\hline Silicone epoxy / PMMA -30\% & 108.1 \\
\hline Silicone epoxy / PMMA -50\%
\end{tabular}

Table 6: Tan $\delta$ loss modulus values of Silicone epoxy / PMMA semi IPNs:

\begin{tabular}{|c|c|c|}
\hline Sample & $\begin{array}{l}\text { Loss modulus, E" } \\
\text { G Pa }\end{array}$ & $\tan \delta$, temp. ${ }^{\circ} \mathrm{C}$ \\
\hline \multicolumn{3}{|l|}{ Semi IPNs } \\
\hline Silicone epoxy / PMMA -10\% & 0.731 & 63.1 \\
\hline Silicone epoxy / PMMA - $30 \%$ & 0.356 & 53.9 \\
\hline Silicone epoxy / PMMA -50\% & 0.496 & 65.6 \\
\hline
\end{tabular}

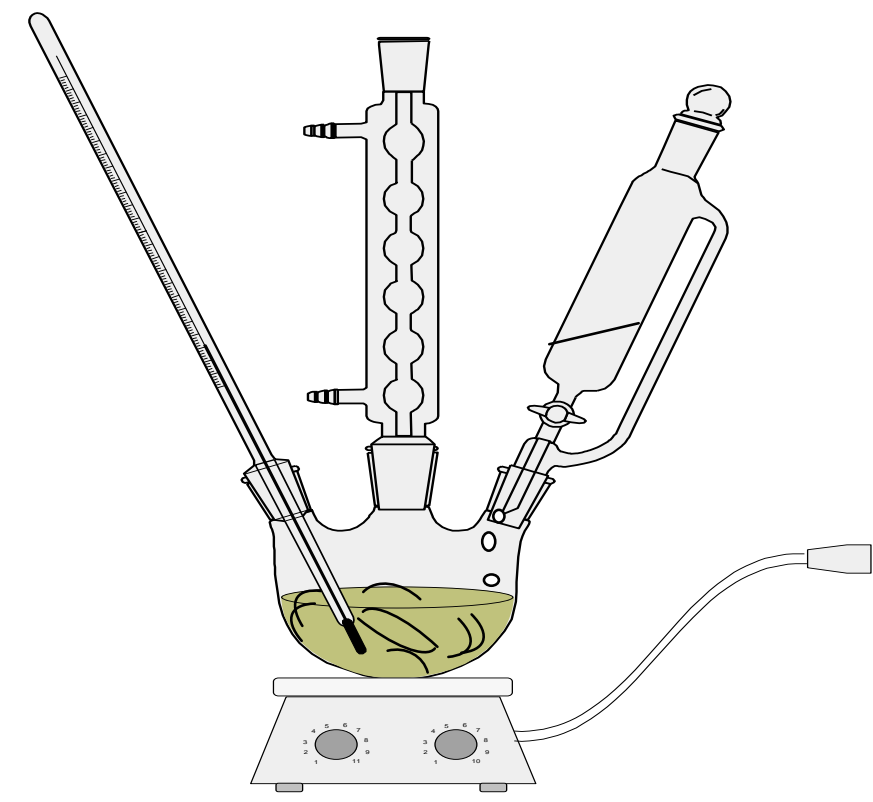

Fig:1 Representation of Synthesis of Silicone Epoxy Resin. 

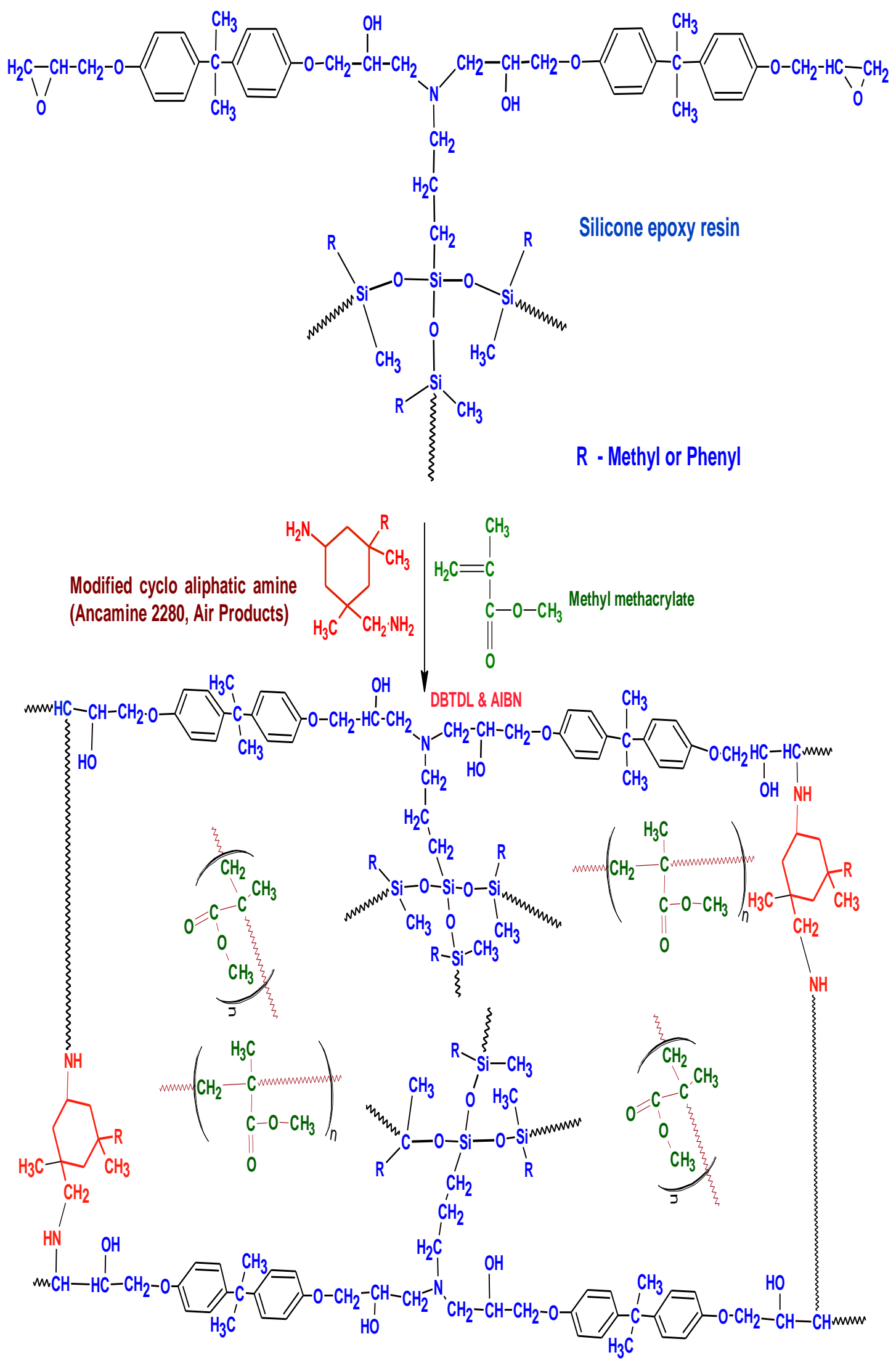

Fig.2 : Silicone epoxy/ poly (methyl methacrylate) semi IPN 


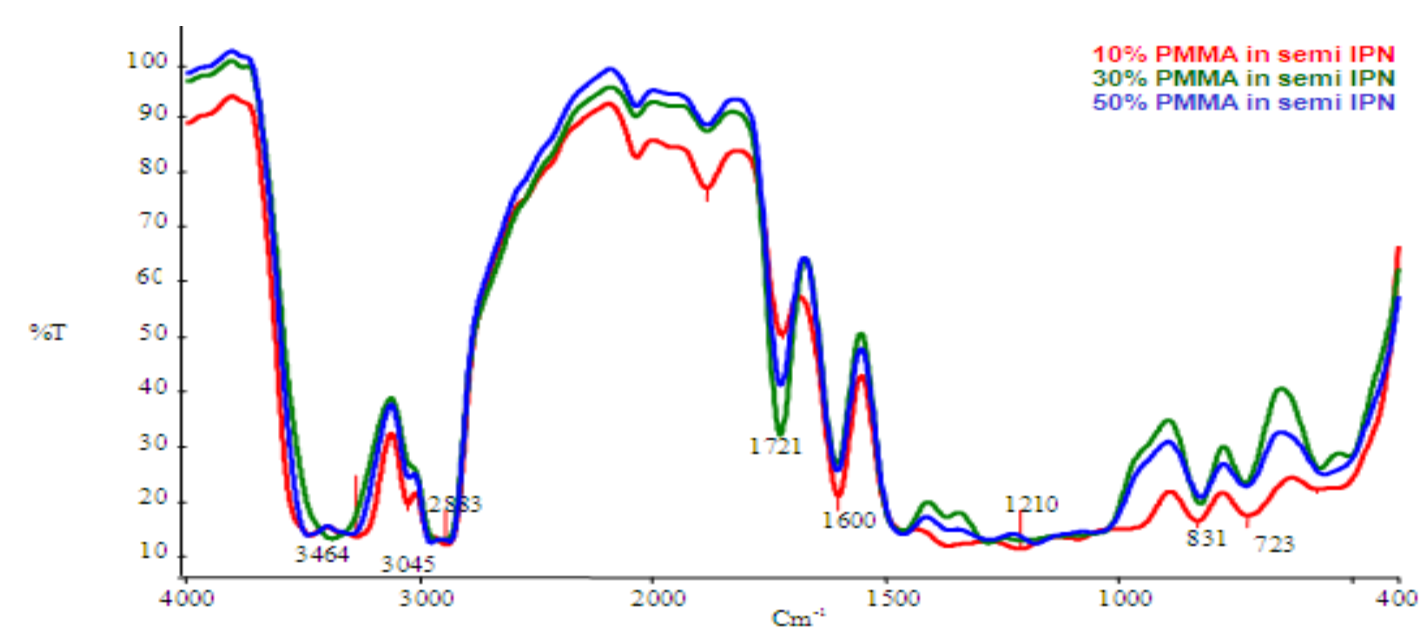

Fig -3: IR Spectra of silicone-epoxy resin/ poly(methyl methacrylate) semi IPNs

Si Epoxy/PMMA semi IPNs-Tensile Properties

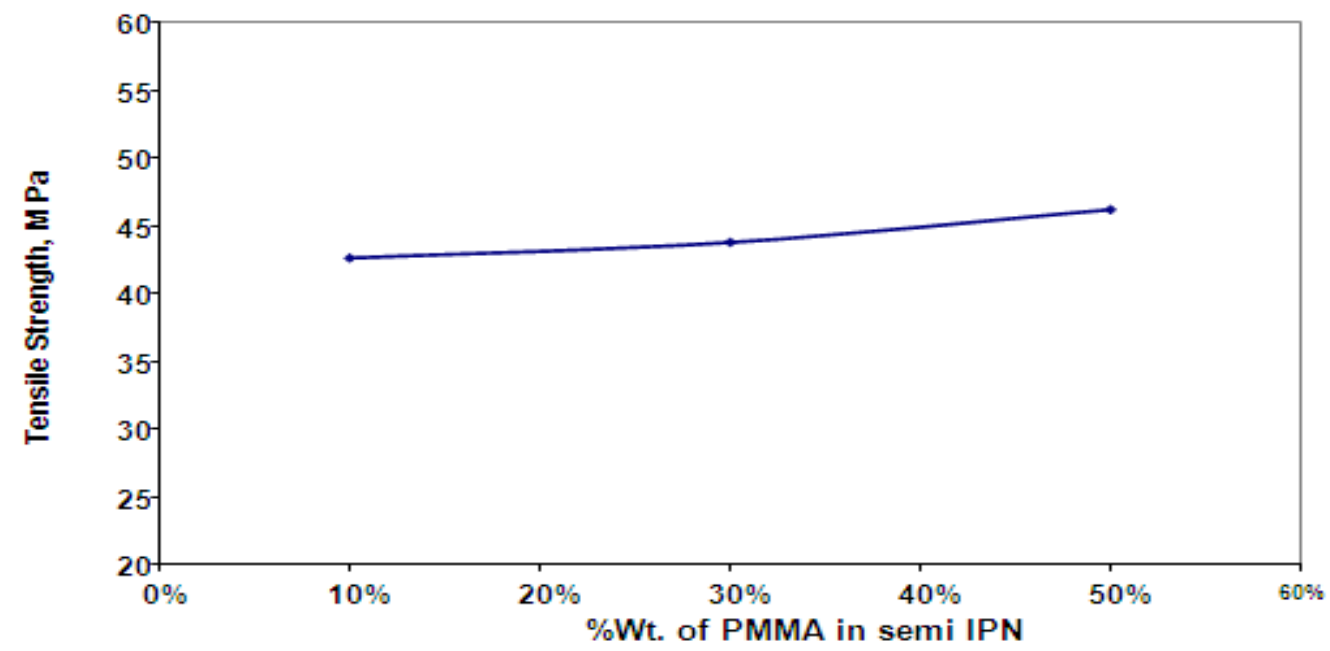

Fig -4: Tensile Strength of silicone epoxy resin/ PMMA semi IPNs

Si Epoxy/PMMA semi IPN -\% Elongation

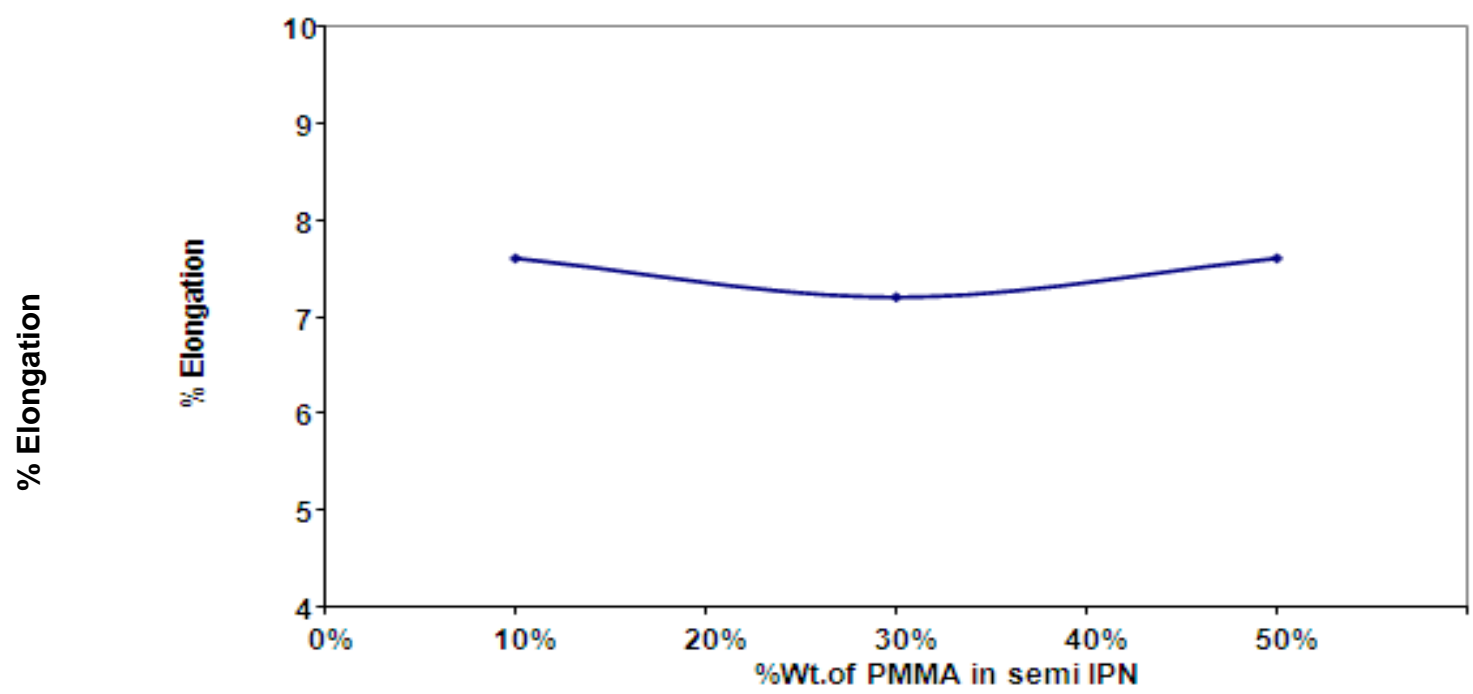

Fig -5: \% Elongation of silicone epoxy resin/ PMMApolysemi IPNs 


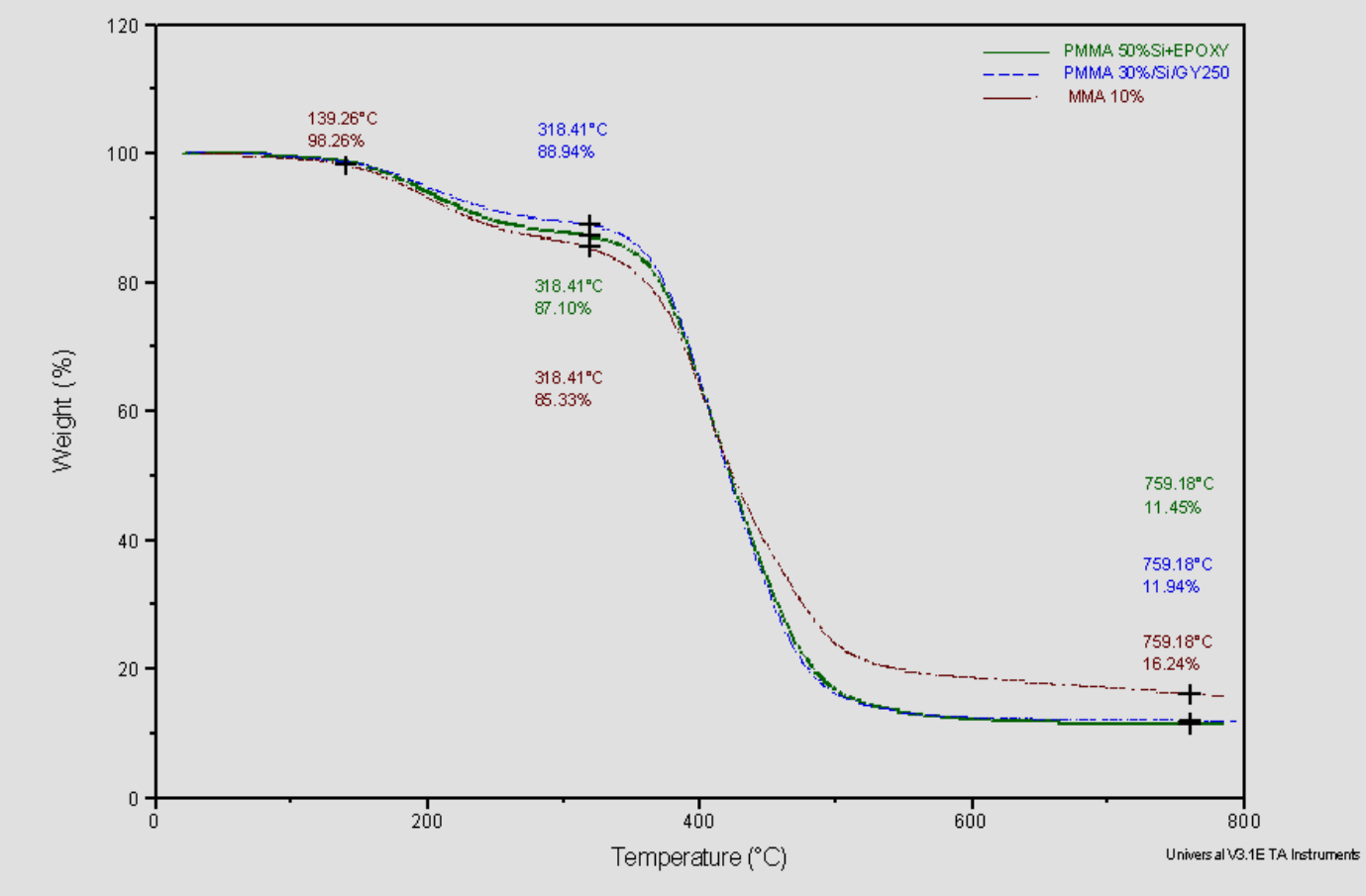

Fig -6: TGA curves of silicone - epoxy resin/ poly (methyl methacrylate) semi IPNs

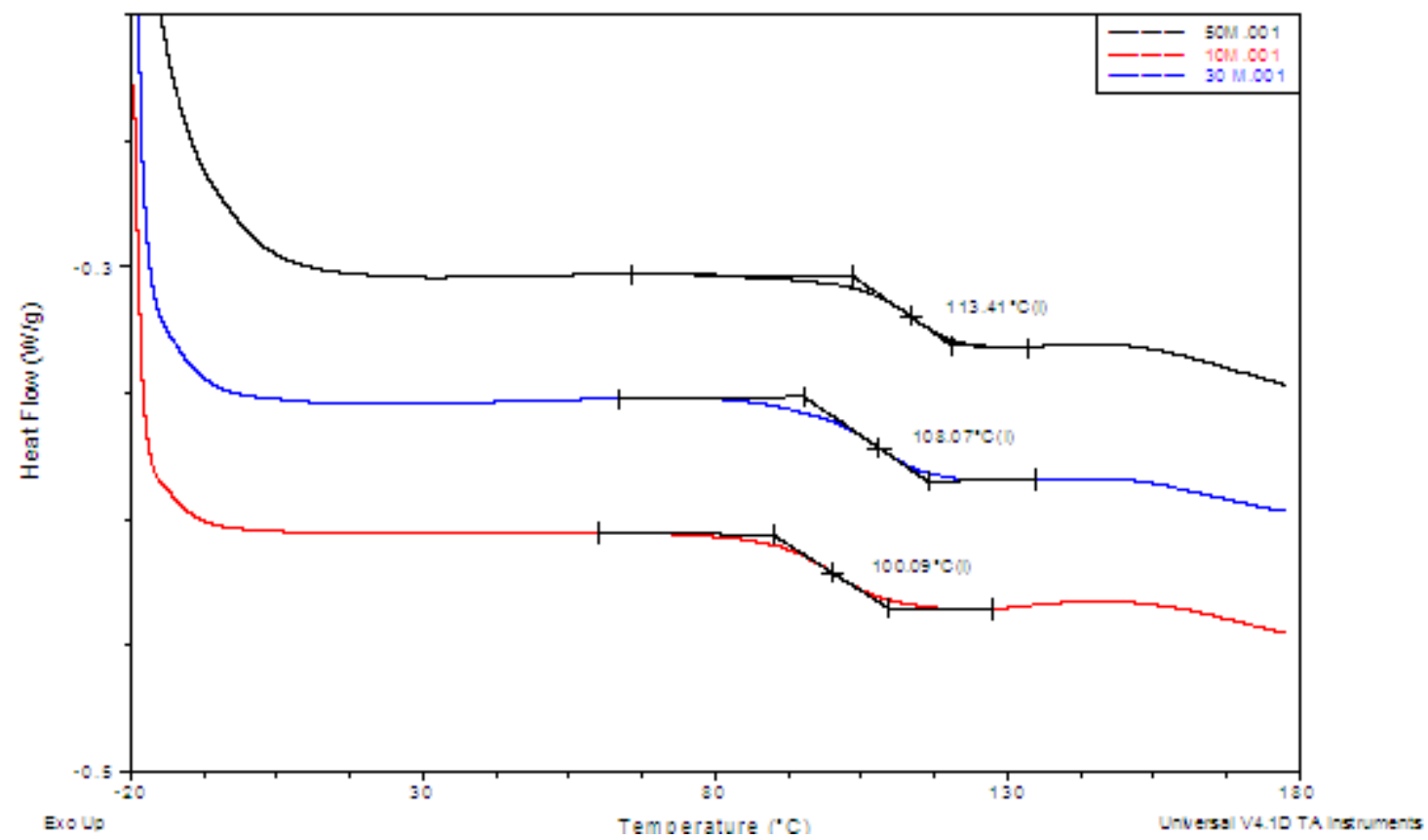

Fig -7: DSC curves of silicone epoxy resin/ poly (methyl methacrylate) semi IPNs 
Tan $\delta$ of Semi IPNs

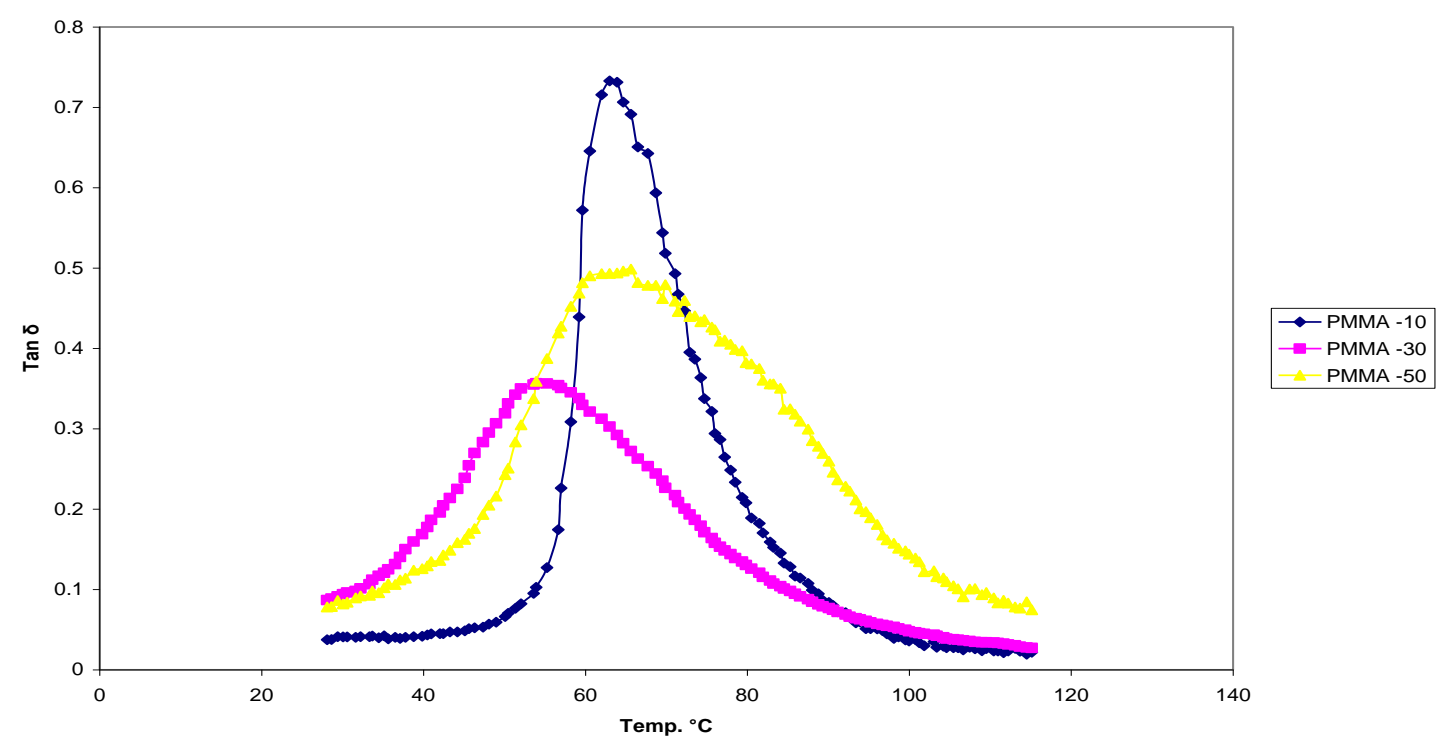

Fig -8: Tan $\delta$ curves of silicone epoxy resin/ poly (methyl methacrylate) semi IPNs

\section{E' of Semi IPNs}

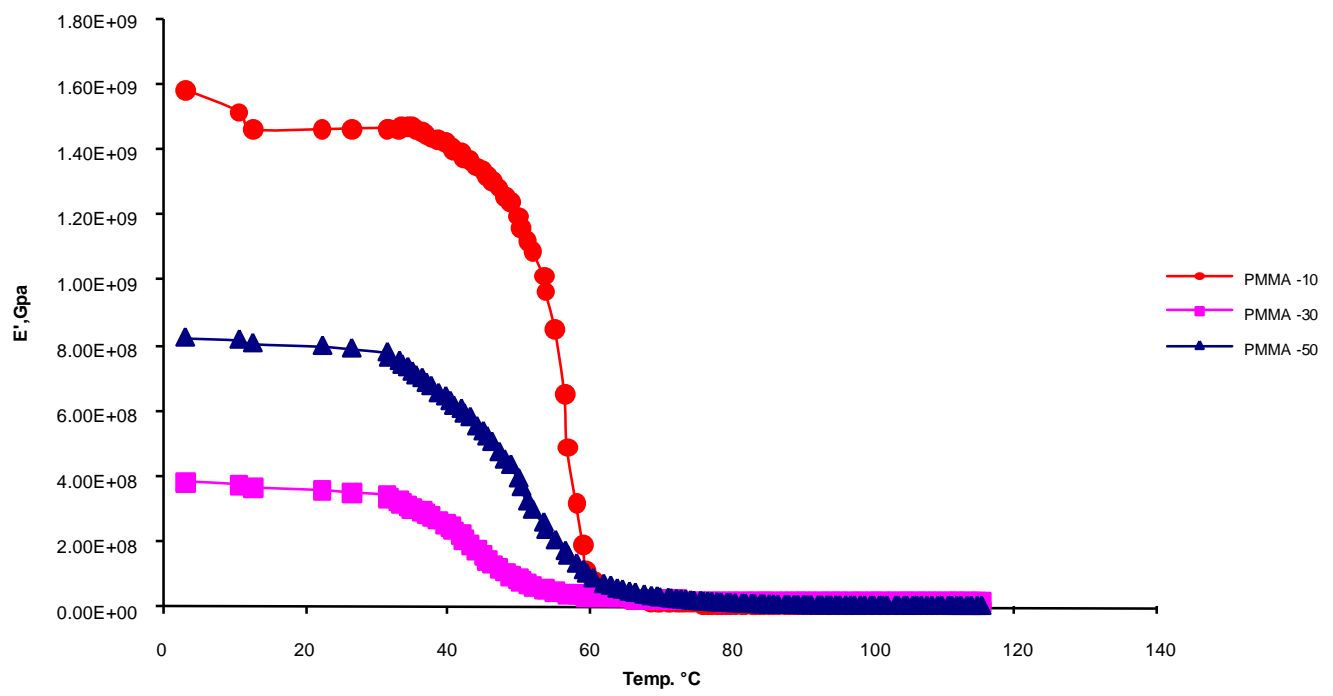

Fig -9: E' curves of silicone epoxy resin/ poly (methyl methacrylate) semi IPNs 


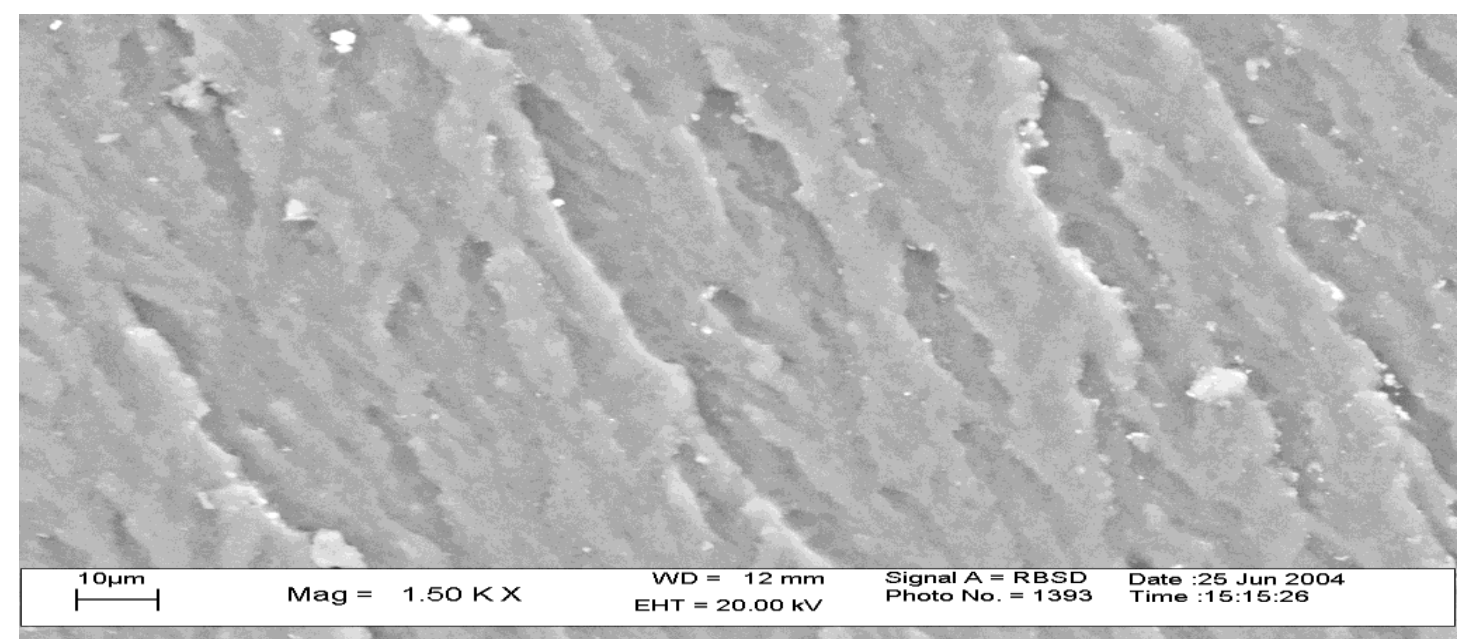

Fig.10: SEM image for silicone epoxy resin

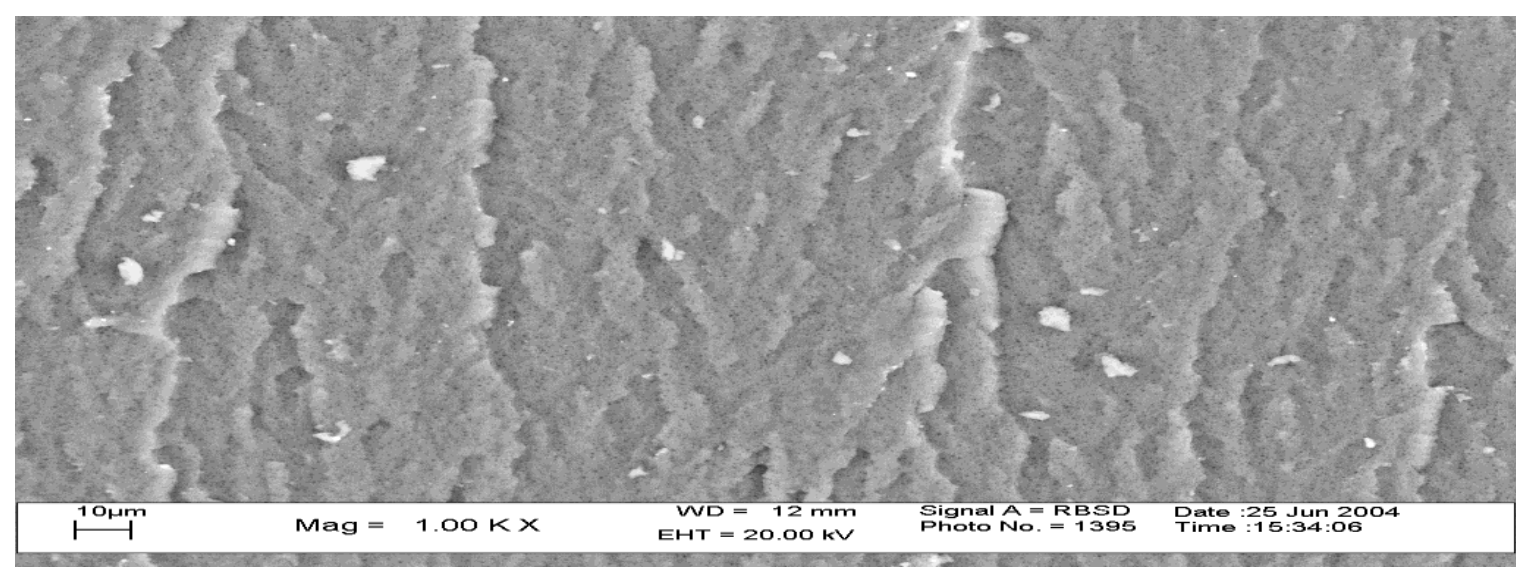

Fig -11: SEM micrograph of silicone - epoxy resin/ poly (methyl methacrylate -10\%) semi IPN

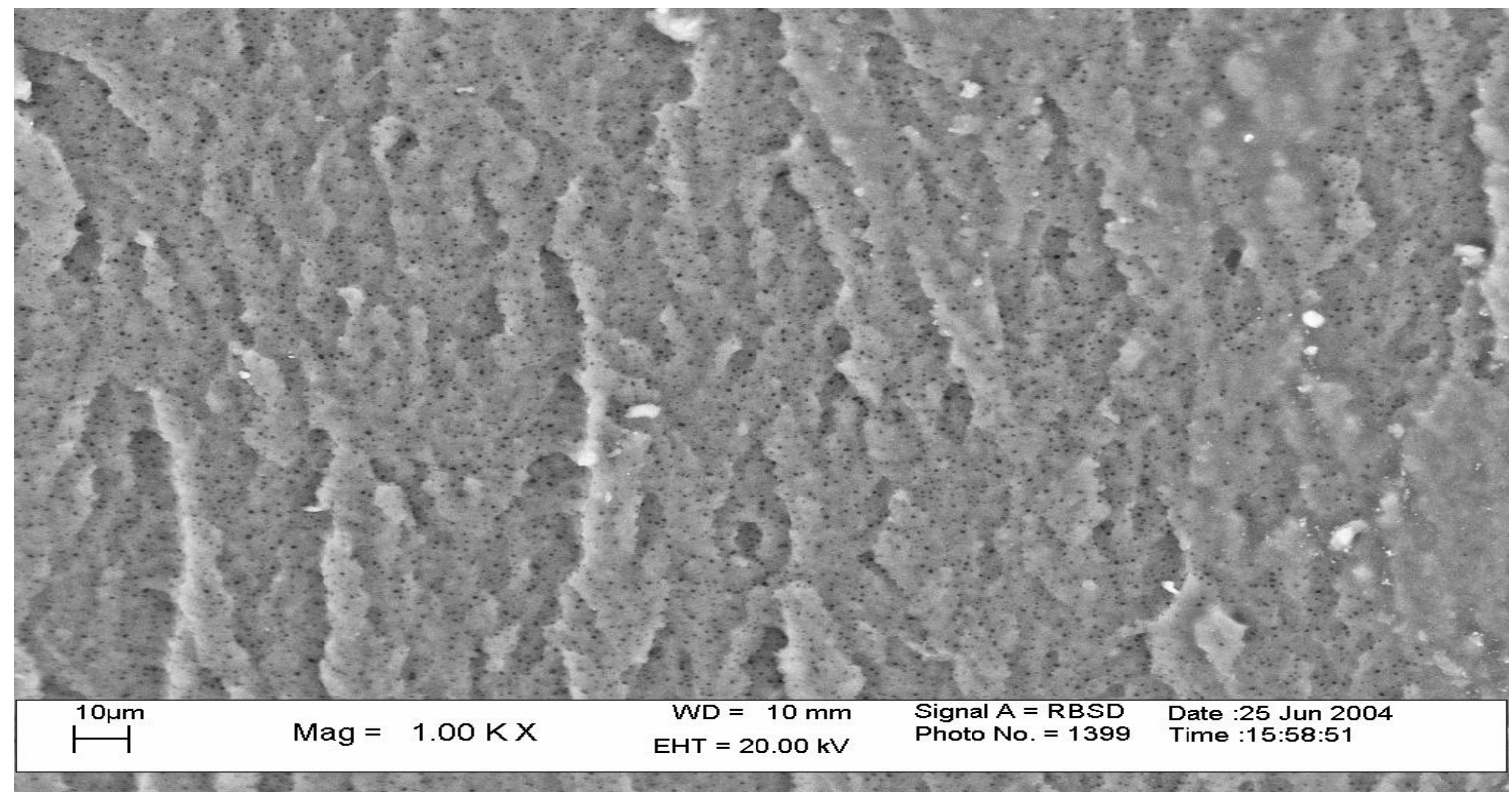

Fig -12: SEM micrograph of silicone - epoxy resin/ poly (methyl methacrylate -30\%)semi IPN 


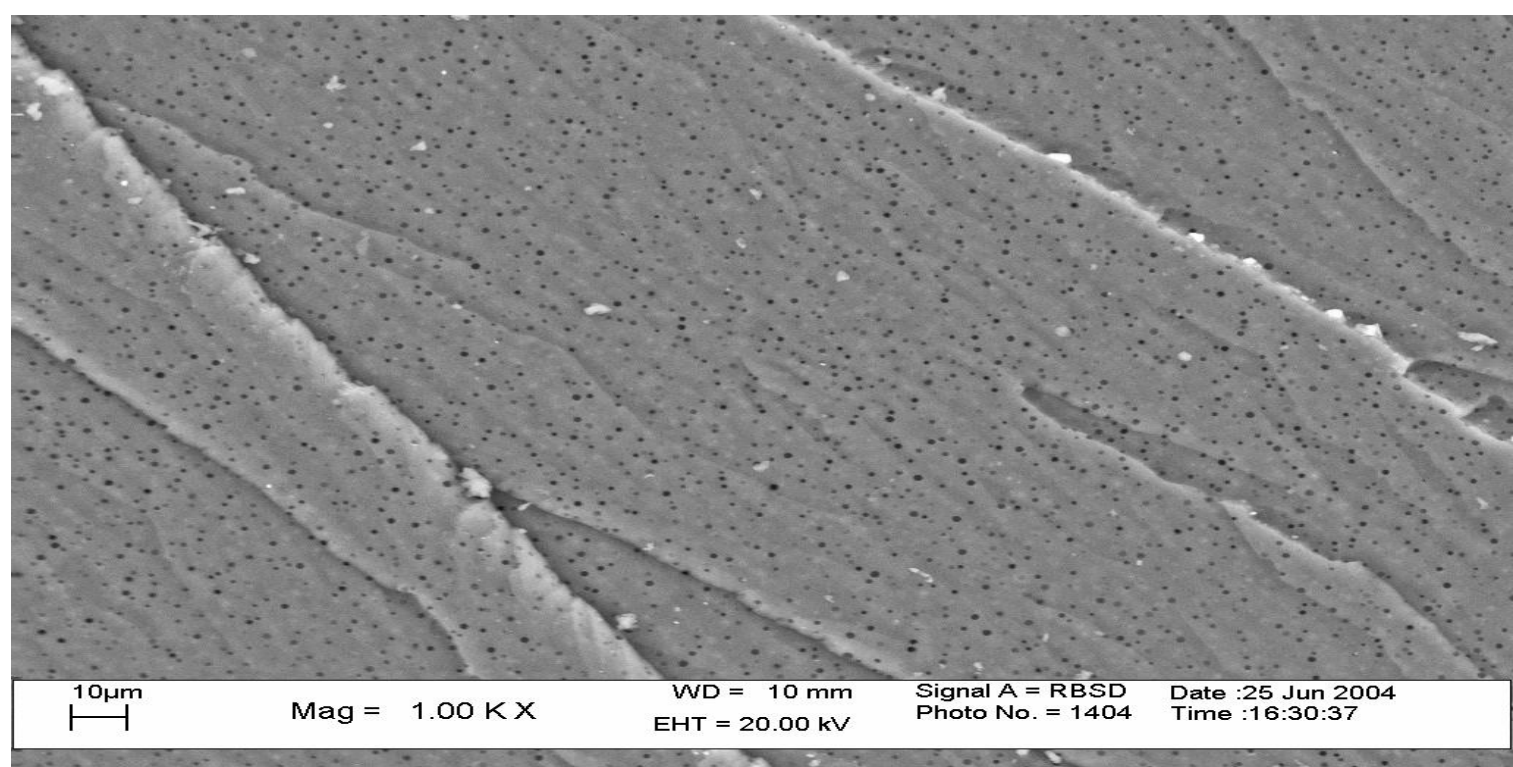

Fig-13: SEM micrograph of silicone epoxy resin/ poly (methyl methacrylate -50\%)semi IPN

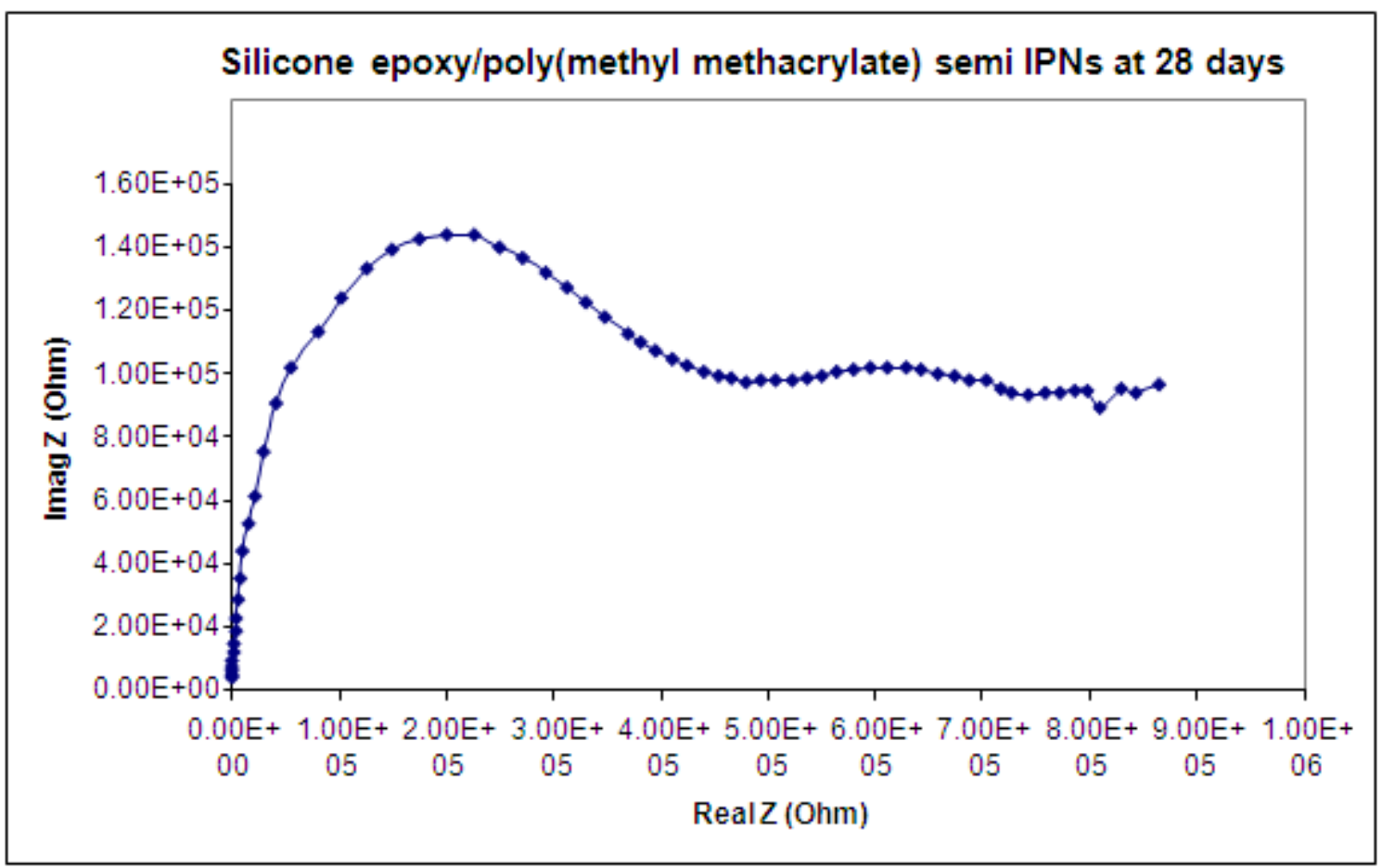

Fig -14: EIS cure (Nyquist) of silicone epoxy resin/ poly (methyl methacrylate -30\%)semi IPN 